\title{
HIV and AIDS: 20 years of science
}

\author{
Anthony S Fauci \\ From the identification of HIV as the agent that causes AIDS, to the development of effective antiretroviral drugs, \\ the scientific achievements in HIV research in the past $\mathbf{2 0}$ years have been formidable. Some of the other important \\ areas of accomplishment include the development of blood tests for HIV and increased knowledge of the molecular \\ virology, epidemiology and pathogenesis of this virus.
}

$T^{\mathrm{t}}$ he pandemic of HIV infection, the cause of AIDS, is clearly the defining medical and public health issue of our generation and ranks among the greatest infectious disease scourges in history ${ }^{1}$. Since the world first became aware of AIDS in the summer of 1981 (refs. 2,3), the disease has spread in successive waves in various regions around the globe. By 2003, HIV had infected a cumulative total of more than 60 million people, over a third of whom subsequently died ${ }^{4}$. Unfortunately, the catastrophic potential of the AIDS pandemic has not yet been fully realized. HIV and AIDS continue to exact an enormous toll throughout the world, notably in sub-Saharan Africa, and their incidence is accelerating in some countries and regions, including China, India and parts of eastern Europe and central Asia ${ }^{4}$.

Commensurate with the magnitude of the HIV and AIDS problem has been the extraordinary scientific effort to delineate the etiology, molecular virology, natural history, epidemiology and pathogenesis of disease caused by HIV (reviewed in refs. 5-8). These areas have paved the way for the development of effective therapies and tools of prevention that have provided enormous benefits to individuals and communities in resource-rich countries and increasingly also in resource-poor countries.

As we look back on the 20 years since the identification in 1983 of HIV as the etiological agent of $\operatorname{AIDS}^{9,10}$, it is appropriate to reflect on some of the many accomplishments in AIDS science, as well as the numerous challenges that remain. Thousands

National Institute of Allergy and Infectious Diseases, National Institutes of Health, Department of Health and Human Services, Bethesda, Maryland 20892-2520, USA. of investigators in diverse disciplines have contributed to an effort that has resulted in an extraordinary, but still incomplete, mosaic of understanding with regard to HIV and AIDS. The collective output of the HIV and AIDS research community has been prodigious: more than 125,000 papers related to HIV and AIDS are catalogued in the PubMed database of the National Library of Medicine.

Although it would be impossible to describe all of the important scientific contributions in HIV and AIDS research within the context of a brief commentary, I have attempted to highlight in broad strokes some of the main areas of accomplishment in the fight against HIV and AIDS without attempting to be all-inclusive. Other authors in this focus will discuss these and additional topics in greater detail.

\section{A new disease}

In the summer of 1981, clinicians in New York and California observed among young, previously healthy, homosexual men an unusual clustering of cases of rare diseases, notably Kaposi sarcoma and opportunistic infections such as Pneumocystis carinii pneumonia, as well as cases of unexplained, persistent lymphadenopathy ${ }^{2,3}$. It soon became evident that these individuals had a common immunological deficit in cell-mediated immunity, resulting predominantly from a significant diminution of circulating $\mathrm{CD}^{+}{ }^{+} \mathrm{T}$ cells ${ }^{11,12}$. Early suggestions that AIDS resulted from behavior specific to gay men were largely dismissed when the syndrome was observed in distinctly different groups in the United States.

After several false leads, many investigators concluded that the clustering of AIDS cases and their occurrence in diverse risk groups could be explained only if AIDS were caused by an infectious microorganism transmitted by intimate contact, for example through sexual activity or blood ${ }^{13}$. As with many emerging infectious diseases, the initial and most powerful tool to illuminate the etiology of the disease was classic epidemiology. Initial observations regarding the immunopathogenesis of AIDS, together with a growing understanding of human and animal retroviruses, suggested that the disease might have a retroviral etiology 9,10 . Two retroviruses, human T-lymphotrophic virus (HTLV)-I and HTLV-II, which had been recently recognized at that time, were the only viruses known to preferentially infect $\mathrm{CD} 4^{+} \mathrm{T}$ cells. The transmission pattern of HTLV was similar to that seen among individuals with AIDS; in addition, HTLV-I and related retroviruses were known to cause varying degrees of immune deficiency in humans and animals ${ }^{14}$. Thus, the search for a new retrovirus was undertaken in earnest.

In 1983, experimental data indicating an association between a retrovirus and AIDS were published by a research team in France led by Luc Montagnier ${ }^{15}$. In 1984, the French group and researchers at the US National Institutes of Health, led by Robert C. Gallo, published seminal papers that established, with virological and epidemiological evidence, that the virus now known as HIV was the cause of AIDS ${ }^{9,10}$. The virus was also isolated independently by Jay Levy in California from both individuals affected with AIDS and asymptomatic individuals from groups at high risk for AIDS ${ }^{16}$.

As is very often the case in science, the identification of HIV drew heavily on many previous advances, in particular the discovery in the 1970s of the reverse transcriptase enzyme used in the replication cycle of retroviruses ${ }^{17}$ and the cytokine interleukin-2, which is required for the robust growth of cul- 


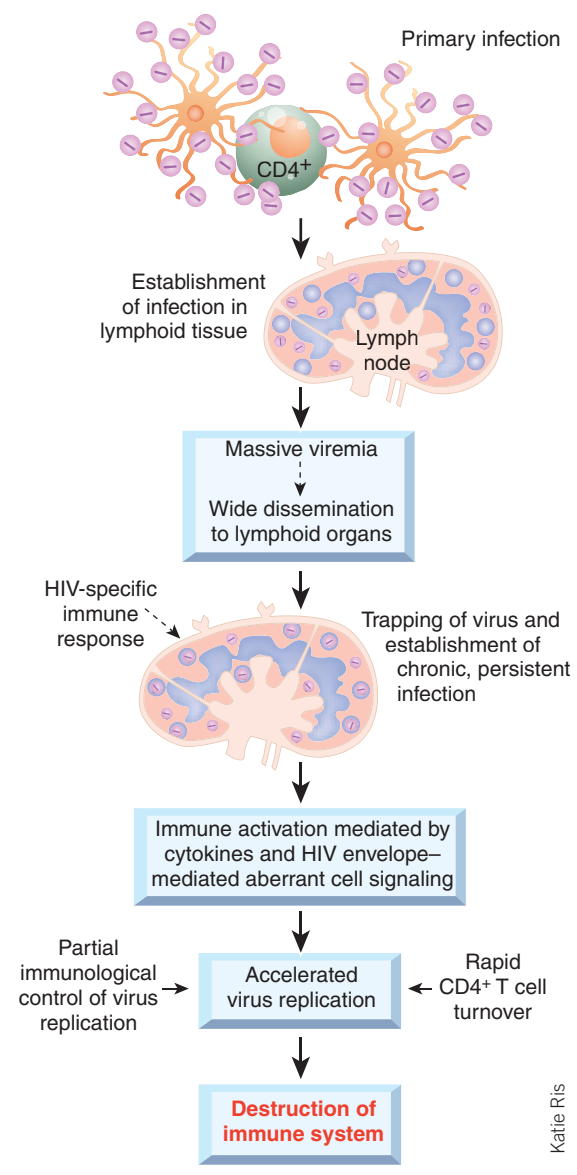

Figure 1 Pathogenic events in untreated HIV-mediated disease. HIV (pink) enters the body and binds to Langerhans or dendritic cells (orange), which carry the virus to $\mathrm{CD} 4^{+} \mathrm{T}$ cells. Infected $\mathrm{CD}^{+} \mathrm{T}$ cells home to lymphoid tissue, where the infection is established. Virus replication accelerates, and massive viremia leads to the wide dissemination of virus throughout the body's lymphoid tissue. An HIV-specific immune response occurs and virus is trapped on the follicular dendritic cells of germinal centers in the lymphoid tissue. At this point, chronic, persistent infection is established despite an immunological response to the virus. Immune activation is an important driver of HIV replication and is mediated by the secretion of various cytokines and by aberrant cell signaling caused by interaction of the viral envelope with cellular receptors. Because there is usually only partial immunological control of virus replication, continual and accelerated production of virus ensues. This is associated with a rapid turnover of $\mathrm{CD}^{+}{ }^{+} \mathrm{T}$ cells. Ultimately, lymphocyte depletion occurs, along with destruction of the architecture of lymphoid tissue. Adapted with permission from ref. 6 .

tured $\mathrm{T}$ cells essential to the propagation of large quantities of HIV in the laboratory ${ }^{18}$.

\section{Molecular virology and epidemiology}

The identification of HIV led to intense activity in the field of molecular virology that con- tinues to the present time. Three structural and six regulatory genes, which together encode at least 15 viral proteins, were identified and their relationship to the complex mechanisms of HIV replication soon unfolded ${ }^{7}$. These findings were crucial to an understanding of the replication cycle of HIV and its relationship to the pathogenic mechanisms of HIV disease. In addition, they provided an avenue to identify important targets for the development of effective antiretroviral drugs.

The study of the molecular virology of HIV also opened the door to the study of the molecular epidemiology of HIV ${ }^{19}$. The science of molecular epidemiology was essential in defining the evolving heterogeneity of HIV throughout the world, including the presence of circulating recombinant forms of the virus $^{20}$ and the origin of HIV in the human species. With regard to the latter, the zoonotic nature of HIV was established by the close phylogenetic relationship between HIV-2, first identified in West African individuals in 1986 (ref. 21), and the simian immunodeficiency virus in sooty mangabeys. In 1999, it was shown that HIV-1 had probably originated from the Pan troglodytes troglodytes species of chimpanzees, in which the virus coevolved over centuries ${ }^{22}$. Because chimpanzees are killed for food in parts of subSaharan Africa, the species jump probably occurred by accident.

\section{A blood test for HIV}

The next critical advance after the identification of HIV was the development of a sensitive and specific test for antibodies to HIV that could be used for diagnosing individuals (with confirmation by immunoblot analysis) and for large-scale screening ${ }^{23}$. This fundamental scientific advance had immediate and profound implications for public health. With an ELISA to detect antibodies to HIV, the blood supplies in the United States and other developed countries were screened for HIV and rendered extremely safe by 1985 (ref. 24), thereby preventing millions of potential transfusion-related infections. HIV antibody tests have subsequently been used in numerous epidemiological and natural history studies to clarify the global scope and evolution of the epidemic ${ }^{25}$. Only with the availability of this simple screening was the real and potential scope of the AIDS pandemic fully appreciated.

Before the ELISA for HIV, clinicians were generally seeing individuals who were in the late stages of disease and had a life expectancy measured in months ${ }^{26}$. The availability of the blood test allowed investigators to readily identify asymptomatic individuals infected with HIV, to describe more accurately the true clinical course of HIV disease, and to follow the natural history of the disease prospectively in individuals for whom a time of seroconversion could be determined.

\section{HIV pathogenesis}

The pathogenesis of HIV disease, from a virological and immunological standpoint, has been studied intensively and defined progressively over the past 20 years ${ }^{6,8}$. The pathogenic mechanisms of HIV disease are extremely complex and multifactorial ${ }^{27}$ (Fig. 1). Even before HIV was identified, it was recognized that an apparent paradox existed whereby the immune system was aberrantly activated at the same time that the individual was experiencing immune deficiency ${ }^{5}$. This was later shown to be due to a combination of the aberrant secretion of various cytokines, many of which could upregulate virus expression, and the intensive cell signaling induced by the viral envelope ${ }^{28}$. Depletion of $\mathrm{CD} 4^{+} \mathrm{T}$ cells was recognized as a hallmark of disease early on ${ }^{11,12}$, even before the classic demonstration in 1984 that the CD4 molecule was the primary receptor for the virus on a subset of T cells and monocyte $^{29,30}$. In addition, much evidence suggested that other factors were necessary for HIV fusion and entry, but these putative 'coreceptors' remained elusive for several years ${ }^{31}$.

In the mid-1990s, a number of diverse areas of investigation elucidated the roles of the chemokine receptors CXCR4 and CCR5 in the efficient binding and entry of two different strains of HIV-1 called X4 and R5, respectively $y^{6,31}$. Indeed, RANTES, MIP- $1 \alpha$ and MIP- $1 \beta$, the ligands for CCR5, were shown to potently inhibit the binding of virus to its target cell. This recognition that HIV could use different coreceptors also helped to explain the occurrence of syncytial (CXCR4-using) and nonsyncytial (CCR5using) variants of HIV ${ }^{6}$. The importance of the CCR5 coreceptor in the pathogenesis of HIV infection was proven by the finding that cells from individuals homozygous for a deletion of 32 base pairs in the CCR5 gene could not be infected in vitro with R5 viruses and that such individuals, who comprise about $1 \%$ of white populations, are extremely resistant to HIV infection even when repetitively exposed to virus ${ }^{32}$.

Studies of lymphoid tissue in individuals infected with HIV revealed the disseminated nature of HIV infection and the fact that lymphoid tissue is indeed the chief target and reservoir of HIV infection ${ }^{33,34}$. In addition, it became clear that HIV continually replicates 


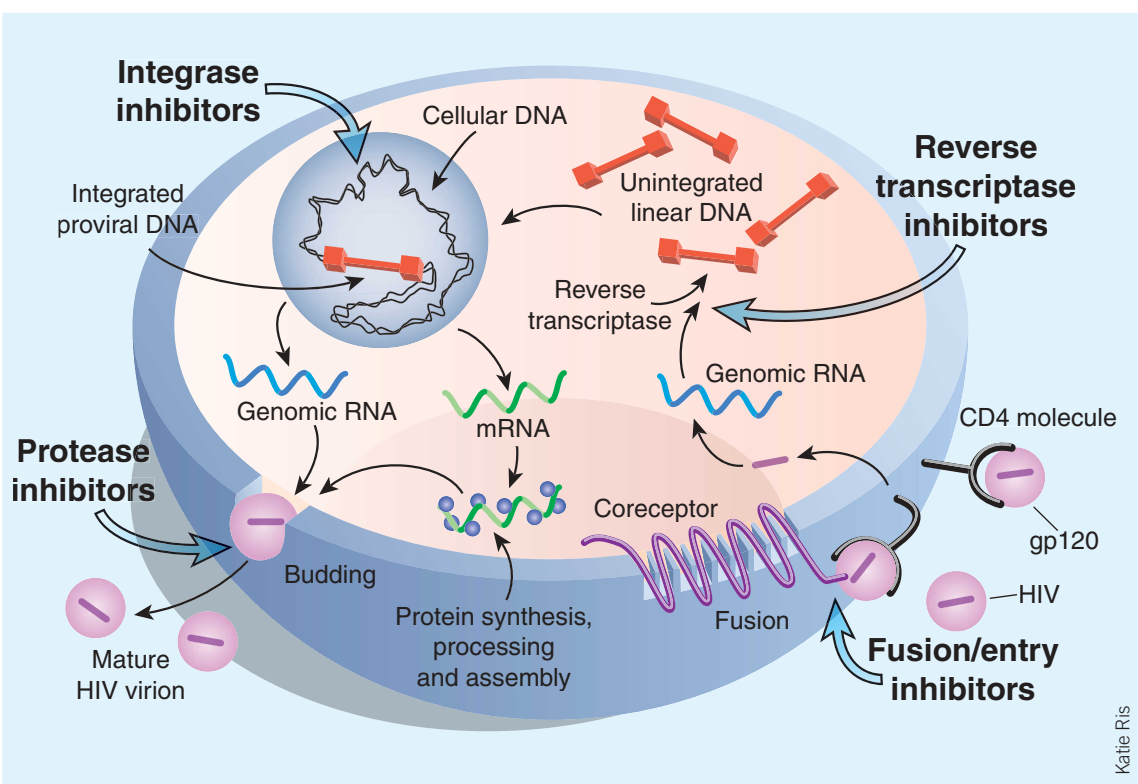

Figure 2 The replication cycle of HIV and targets for antiretroviral therapy.

at varying degrees in lymphoid tissue despite the fact that the individual might appear to be clinically well. Although the clinical course varied widely among individuals, the inexorably progressive nature of disease in most individuals became clear.

An important advance in HIV research has been the development of highly sensitive techniques for the precise quantification of small amounts of nucleic acids ${ }^{35}$. The measurement of serum or plasma levels of HIV RNA is now an essential component of the monitoring of individuals with HIV infection and, together with $\mathrm{CD} 4^{+} \mathrm{T}$ cell counts, guides therapeutic decisions ${ }^{36}$. Assays such as RT-PCR and the bDNA technique for directly detecting HIV RNA have helped to clarify the direct relationship between amounts of virus and rates of disease progression, rates of viral turnover, the relationship between immune system activation and viral replication, and responsiveness to therapy $^{6}$.

The ability to measure plasma viremia precisely led to the classic viral dynamics studies of Ho and Shaw in 1995, which characterized the enormous turnover of virus in HIV disease and the delicate balance between virus production and $\mathrm{T}$ cell dynamics $^{37,38}$. These studies led to a cascade of insights into HIV pathogenesis, among them an appreciation of the direct relationship between virus replication and disease progression and the association of a given viral set point in an untreated individual with the prognosis for disease progression ${ }^{39}$. The latter observation has been essential in the design of therapeutic strategies and has guided clinicians in decisions regarding the initiation and modification of therapeutic regimens ${ }^{36}$.

The finding of latent reservoirs of HIV, particularly in the resting subset of $\mathrm{CD} 4^{+} \mathrm{T}$ cells, has had a sobering effect on hopes of eradicating HIV in individuals whose viral load is rendered 'undetectable' by antiretroviral therapy ${ }^{40}$. Indeed, simple but defining studies have shown that even in individuals in whom plasma viremia is driven by antiretroviral therapy to levels of less than 50 copies of RNA per ml ('undetectable') for up to 3 years, the viral reservoir persists and the virus rebounds from this reservoir within weeks of discontinuing therapy ${ }^{41}$.

Studies of the immune response to productive and frustrating. Clearly, individuals in whom HIV infection has been established cannot eliminate the virus from their this consistent observation, individuHIV have been both bodies $^{40,41}$. Despite

als infected with HIV also show several elements of HIV-specific immunity. Neutralizing antibodies, potent $\mathrm{HIV}$-specific $\mathrm{CD}^{+}$ cytotoxic $\mathrm{T}$ cell responses and HIV-specific $\mathrm{CD} 4^{+} \mathrm{T}$ cells are present in many individuals infected with HIV at various stages of disease $^{6}$. Unfortunately, CD ${ }^{+}$cytotoxic T cells select for escape mutants, and the most effective neutralizing antibodies are directed at cryptic epitopes against which it is difficult to induce antibodies. Although $\mathrm{CD} 4^{+} \mathrm{T}$ cells capable of undergoing lymphocyte blast transformation to HIV antigens are more likely to be seen in individuals in the early stages of disease, the induction of such responses has minimal, if any, effect on disease progression 6 .

Thus, the initial hope that the identification of HIV-specific elements of the immune system in HIV-infected individuals would lead to better therapies and vaccines has been replaced by the realization that we have yet to identify a clear correlate of protective immunity against HIV infection ${ }^{42}$. Understanding the correlates of immune protection and their potential role in vaccine development remains one of the greatest challenges in HIV and AIDS research.

\section{Therapy for HIV infection}

Second to the identification of HIV as the causative agent for AIDS, the most impressive scientific advances have occurred in the development of effective antiretroviral drugs for treating individuals infected with HIV.

Table 1 Antiretroviral drugs licensed by the US FDA

\section{Drug}

Retrovir (zidovudine, AZT)

Videx (didanosine, ddl)

Hivid (zalcitabine, ddC)

Zerit (stavudine, $\mathrm{d} 4 \mathrm{~T}$ )

Epivir (lamivudine, 3TC)

Invirase (saquinavir-HGC)

Norvir (ritonavir)

Crixivan (indinavir)

Viramune (nevirapine)

Viracept (nelfinavir)

Rescriptor (delavirdine)

Combivir (AZT and 3TC)

Fortovase (saquinavir-SGC)

Sustiva (efavirenz)

Ziagen (abacavir)

Agenerase (amprenavir)

Kaletra (lopinavir and ritonavir)

Trizivir (AZT + 3TC + abacavir)

Viread (tenofovir)

Fuzeon (enfuvirtide, T-20)
Approval date

March 1987

October 1991

June 1992

June 1994

November 1995

December 1995

March 1996

March 1996

June 1996

March 1997

April 1997

September 1997

November 1997

September 1998

December 1998

April 1999

September 2000

November 2000

October 2001

March 2003 
The spectrum of drug discovery for HIV centers on an appreciation of vulnerable targets in the replication cycle of the virus (Fig. 2). The first effective drug against HIV was the reverse transcriptase inhibitor azidovudine (zidovudine), or $\mathrm{AZT}^{43}$. It was identified by a screening process using large numbers of compounds that had been already produced for other purposes. AZT was originally developed as an anticancer drug but did not prove effective in that capacity. It was licensed instead as the first antiretroviral drug in 1987.

Subsequently, more sophisticated science in the form of targeted drug design has been the rule as drugs have been developed to target specific vulnerable points in the virus replication cycle, providing a cogent example of the importance of the basic research endeavors in viral biology and the translational approaches in drug development ${ }^{44}$. The prototype of this approach was the expression, purification and crystallization of the HIV protease enzyme to facilitate the tailored design of protease inhibitors - a class of antiretroviral drug that was first approved by the US Food and Drug Administration (FDA) in 1995 (ref. 45).

The newest class of drug, fusion inhibitors, represents another example of successful targeted drug development led by basic science discovery ${ }^{44}$. These compounds block the fusion of the viral envelope to the cell membrane, and became available with the FDA approval of enfuvirtide (Fuzeon) in 2003 (ref. 46). New and improved drugs in all three classes (reverse transcriptase inhibitors, protease inhibitors, and fusion and entry inhibitors) are being actively pursued along with drugs against alternative targets such as the viral integrase ${ }^{44}$. Currently, there are 20 FDA-approved drugs or combinations of drugs for HIV (Table 1). The availability of these therapeutics and their use in combinations of three or more drugs have transformed the treatment of individuals infected with HIV such that morbidity and mortality owing to HIV disease have sharply declined in developed nations where such drugs are readily available ${ }^{25}$.

\section{HIV vaccinology}

The progression of HIV disease in the setting of vigorous anti-HIV responses remains a central paradox in the pathogenesis of HIV infection ${ }^{6,8}$. Elements of both the humoral and cell-mediated immune responses against HIV have been implicated in the partial control of viral replication. Even after 20 years of HIV and AIDS science, however, our lack of understanding of the correlates of protective immunity in HIV infection continues to hamper the rational development of HIV vaccines ${ }^{47}$. With 14,000 individuals worldwide becoming infected with HIV every day ${ }^{4}$, a vaccine that prevents HIV infection or at least slows the progression of disease in individuals who become infected is badly needed.

Despite the lack of a clear understanding of the correlates of protective immunity in HIV infection and other formidable obstacles, significant progress toward an HIV vaccine has been made ${ }^{47}$. At the time of writing, numerous promising HIV vaccine candidates are in various stages of preclinical and clinical development. But it is still not clear at this point how successful, if at all, we will be in the development of a vaccine that truly protects against HIV infection. Candidate vaccines in nonhuman primate models generally have not been able to protect against infection, but they have shown protection (at least for a time) against disease progression in primates that become infected despite having been vaccinated ${ }^{47}$. The superinfection of already-infected individuals whose current virus had been under excellent immunological control is a troubling observation ${ }^{48}$. Clearly, the development of a safe and effective vaccine for HIV is one of the most formidable challenges for research in infectious diseases.

\section{Conclusion}

The scientific accomplishments in the field of HIV research over the past 20 years reflect an extraordinary odyssey of discovery. Indeed, these accomplishments represent a model of what can be accomplished when the world's scientific community is galvanized in a common goal of pitting its best minds and substantial resources against a historic public health challenge. This Nature Medicine special issue will take up in detail these and other crucial accomplishments in the scientific response to HIV and AIDS.

Unfortunately, the HIV pandemic still rages throughout the world, particularly in resource-poor countries such as those in subSaharan Africa, the Caribbean and parts of Asia. This fact should energize the scientific and public health communities to continue the quest for scientific discovery and, simultaneously, to ensure that the fruits of scientific discovery are adequately applied to those most in need.

\section{ACKNOWLEDGMENTS}

I thank G. Folkers for help with preparing the manuscript and H.C. Lane for critically reading the manuscript.

1. Fauci, A.S. The AIDS epidemic — considerations for the 21 st century. N. Engl. J. Med. 341, 1046-1050
(1999)

2. Kaposi's sarcoma and pneumocystis pneumonia among homosexual men-New York City and California. Morb. Mortal. Wkly. Rep. 30, 305-308 (1981).

3. Pneumocystis pneumonia-Los Angeles. Morb. Mort. Wkly. Rep. 30, 250-252 (1981).

4. Joint United Nations Programme on HIV/AIDS (UNAIDS). AIDS epidemic update <http://www. unaids.org/worldaidsday/2002/press/Epiupdate.html> (UNAIDS, Geneva, 2002).

5. Fauci, A.S. The human immunodeficiency virus: infectivity and mechanisms of pathogenesis. Science 239, 617-622 (1988).

6. Fauci, A.S. Host factors and the pathogenesis of HIVinduced disease. Nature 384, 529-534 (1996).

7. Greene, W.C. \& Peterlin, B.M. Charting HIV's remarkable voyage through the cell: basic science as a passport to future therapy. Nat. Med. 8, 673-680 (2002).

8. Rowland-Jones, S.L. Timeline: AIDS pathogenesis: what have two decades of HIV research taught us? Nat. Rev. Immunol. 3, 343-348 (2003).

9. Gallo, R.C. Historical essay. The early years of HIV/AIDS. Science 298, 1728-1730 (2002).

10. Montagnier, L. Historical essay. A history of HIV discovery. Science 298, 1727-1728 (2002).

11. Gottlieb, M.S. et al. Pneumocystis carinii pneumonia and mucosal candidiasis in previously healthy homosexual men: evidence of a new acquired cellular immunodeficiency. N. Engl. J. Med. 305, 1425-1431 (1981).

12. Masur, H. et al. An outbreak of community-acquired pneumocystis carinii pneumonia: initial manifestation of cellular immune dysfunction. N. Engl. J. Med. 305, 1431-1438 (1981).

13. Francis, D.P., Curran, J.W. \& Essex, M. Epidemic acquired immune deficiency syndrome: epidemiologic evidence for a transmissible agent. J. Natl. Cancer Inst. 71, 1-4 (1983).

14. Varmus, H. Retroviruses. Science 240, 1427-1435 (1988).

15. Barre-Sinoussi, F. et al. Isolation of a T-lymphotropic retrovirus from a patient at risk for acquired immune deficiency syndrome (AIDS). Science 220, 868-871 (1983).

16. Levy, J.A. et al. Isolation of lymphocytopathic retroviruses from San Francisco patients with AIDS. Science 225, 840-842 (1984).

17. Raju, T.N. The Nobel chronicles. 1975: Renato Dulbecco (b 1914), David Baltimore (b 1938), and Howard Martin Temin (1934-94). Lancet 354, 1308 (1999).

18. Morgan, D.A., Ruscetti, F.W. \& Gallo, R. Selective in vitro growth of $T$ lymphocytes from normal human bone marrows. Science 193, 1007-1008 (1976).

19. Smith, T.F., Srinivasan, A., Schochetman, G. Marcus, M. \& Myers, G. The phylogenetic history of immunodeficiency viruses. Nature 333, 573-575 (1988).

20. Osmanov, S., Pattou, C., Walker, N., Schwardlander, B. \& Esparza, J. Estimated global distribution and regional spread of HIV-1 genetic subtypes in the year 2000. J. Acquired Immune Defic. Syndr. 29, 184-190 (2002)

21. Clavel, F. et al. Isolation of a new human retrovirus from West African patients with AIDS. Science 233, 343-346 (1986).

22. Gao, F. et al. Origin of HIV-1 in the chimpanzee Pan troglodytes troglodytes. Nature 397, 436-441 (1999).

23. Sarngadharan, M.G., Popovic, M., Bruch, L., Schupbach, J. \& Gallo, R.C. Antibodies reactive with human T-lymphotropic retroviruses (HTLV-III) in the serum of patients with AIDS. Science 224, 506-508 (1984).

24. Perkins, H.A. Safety of the blood supply. J. Clin. Apheresis 8, 110-116 (1993).

25. Joint United Nations Programme on HIV/AIDS (UNAIDS). Report on the Global HIV/AIDS Epidemic <http://www.unaids.org/epidemic_update/ report_july02/index.html> (UNAIDS, Geneva, 2002).

26. Lemp, G.F., Payne, S.F., Neal, D., Temelso, T. \& Rutherford, G.W. Survival trends for patients with 
AIDS. J. Am. Med. Assoc. 263, 402-406 (1990).

27. Fauci, A.S. Multifactorial nature of human immunod eficiency virus disease: implications for therapy. Science 262, 1011-1018 (1993).

28. Kinter, A., Arthos, J., Cicala, C. \& Fauci, A.S Chemokines, cytokines and HIV: a complex network of interactions that influence HIV pathogenesis. Immunol. Rev. 177, 88-98 (2000)

29. Dalgleish, A.G. et al. The CD4 (T4) antigen is an essential component of the receptor for the AIDS retrovirus. Nature 312, 763-767 (1984).

30. Klatzmann, D. et al. T-lymphocyte T4 molecule behaves as the receptor for human retrovirus LAV. Nature 312, 767-768 (1984)

31. D'Souza, M.P. \& Harden, V.A. Chemokines and HIV-1 second receptors. Confluence of two fields generates optimism in AIDS research. Nat. Med. 2 1293-1300 (1996).

32. O'Brien, S.J. \& Moore, J.P. The effect of genetic variation in chemokines and their receptors on HIV transmission and progression to AIDS. Immunol. Rev. 177, 99-111 (2000).

33. Embretson, J. et al. Massive covert infection of helper T lymphocytes and macrophages by HIV dur- ing the incubation period of AIDS. Nature 362 , 359-362 (1993)

34. Pantaleo, G. et al. HIV infection is active and progressive in lymphoid tissue during the clinically latent stage of disease. Nature 362, 355-358 (1993).

35. Piatak, M. Jr. et al. High levels of HIV-1 in plasma during all stages of infection determined by competitive PCR. Science 259, 1749-1754 (1993).

36. Dybul, M., Fauci, A.S., Bartlett, J.G., Kaplan, J.E. \& Pau, A.K. Guidelines for using antiretroviral agents among HIV-infected adults and adolescents. Recommendations of the Panel on Clinical Practices for Treatment of HIV. MMWR Recomm. Rep. 51, $1-55$ (2002).

37. Ho, D.D. et al. Rapid turnover of plasma virions and CD4 lymphocytes in HIV-1 infection. Nature $\mathbf{3 7 3}$ 123-126 (1995)

38. Wei, X. et al. Viral dynamics in human immunodeficiency virus type 1 infection. Nature 373, 117-122 (1995).

39. Mellors, J.W. et al. Quantitation of HIV-1 RNA in plasma predicts outcome after seroconversion. Ann. Intern. Med. 122, 573-579 (1995).

40. Blankson, J.N., Persaud, D. \& Siliciano, R.F. The challenge of viral reservoirs in HIV-1 infection. Annu. Rev. Med. 53, 557-593 (2002).

41. Chun, T.W. \& Fauci, A.S. Latent reservoirs of HIV: obstacles to the eradication of virus. Proc. Natl. Acad. Sci. USA 96, 10958-10961 (1999).

42. Haynes, B.F., Pantaleo, G. \& Fauci, A.S. Toward an understanding of the correlates of protective immunity to HIV infection. Science 271, 324-328 (1996).

43. McLeod, G.X. \& Hammer, S.M. Zidovudine: five years later. Ann. Intern. Med. 117, 487-501 (1992)

44. Gulick, R.M. New antiretroviral drugs. Clin. Microbiol. Infect. 9, 186-193 (2003).

45. Flexner, C. HIV-protease inhibitors. N. Engl. J. Med. 338, 1281-1292 (1998).

46. Burton, A. Enfuvirtide approved for defusing HIV. Lancet Infect. Dis. 3, 260 (2003).

47. Nabel, G.J. Challenges and opportunities for development of an AIDS vaccine. Nature 410, 1002-1007 (2001)

48. Goulder, P.J. \& Walker, B.D. HIV-1 superinfection-a word of caution. N. Engl. J. Med. 347, 756-758 (2002) 